\title{
Influence of Leg Support Elevation on Horizontal Force Acting on the Buttocks in a Reclining Wheelchair in Different Rotational Axis Positions of the Back Support
}

\author{
Kenichi Kobara*, Daisuke Fujita, Hiroshi Osaka, Hisashi Takahashi, Tadanobu Suehiro, Tomotaka Ito and Susumu Watanabe \\ Department of Rehabilitation, Faculty of Health Science and Technology, Kawasaki University of Medical Welfare, Japan
}

"Corresponding author: Kenichi Kobara, Department of Rehabilitation, Faculty of Health Science and Technology, Kawasaki University of Medical Welfare, Japan, Tel: +81 86462 1111; Fax: +81 86464 1109; E-mail: rptkob@mw.kawasaki-m.ac.jp

Received date: September 7, 2015; Accepted date: October 10, 2015; Published date: October 19, 2015

Copyright: ( 2015 Kobara K, et al. This is an open-access article distributed under the terms of the Creative Commons Attribution License, which permits unrestricted use, distribution, and reproduction in any medium, provided the original author and source are credited.

\begin{abstract}
Purpose: The purpose of this study was to investigate how the influences of leg support elevation on the horizontal force acting on the buttocks in a reclining wheelchair changes in various rotational axis positions of the back support.

Materials and methods: The participants were 13 healthy men. The horizontal force was measured using a force plate on the experimental chair. Four experimental conditions were tested: the leg-down condition in the rearaxis and trochanter- axis positions of back support and the leg-up condition in the rear-axis and the trochanter-axis positions. The back support was reclined at increasing angles, beginning with the initial upright position (IUP) and proceeding to the fully reclined position (FRP). We calculated the variation rate of the forces acting on the buttocks between the FRP and the IUP (FRP/IUP*100: \%).
\end{abstract}

Results: In the trochanter-axis position, the variation rate of the leg-down and the leg-up conditions was $155.6 \pm$ $29.1 \%$ and $119.3 \pm 10.7 \%$, respectively. In the rear-axis position, the variation rate of the leg-down and the leg-up condition were $100.7 \pm 16.7 \%$ and $96.3 \pm 10.2 \%$, respectively. There were significant differences in the variation rate between the leg-down and leg-up conditions in the trochanter-axis position, but there were not significant differences in the rear-axis position.

Conclusion: The extent of the influence of leg support elevation on the horizontal force acting on the buttocks in a reclining wheelchair decreases when the rotational axis of the back support is placed close to the trochanter.

Keywords: Elevate leg support; Horizontal force; Rotational axis position of back support

\section{Introduction}

Decubitus ulcers, also called bedsores or pressure ulcers, are a serious health problem. The North American National Pressure Ulcer Advisory Panel defines a decubitus ulcer as a localized injury to the skin and/or underlying tissue that usually occurs over a bony prominence due to pressure or pressure in combination with shear force and friction [1]. Husain [2] reported that the tolerance of tissue to an external load depends on the duration of the external load. The external load, which may be due to pressure, friction, and/or shear force, is an important factor in decubitus ulcer formation. Although seemingly innocuous, friction and shear force can increase the risk of clinical injury, which is a concern for both patients and practitioners [3].

Wheelchairs with reclining back supports are often used for individuals with leg and trunk disorders, including post-apoplectic hemiplegia and spinal cord injuries, and these individuals have a high risk of decubitus ulcer formation. Therefore, it is important to evaluate the reduction in the shear force acting on the buttocks when such a wheelchair's back support is reclined. In previous research [4-6], we investigated the functions that reclining wheelchairs should possess to reduce the shear force acting on the buttocks by reclining the back support. The results obtained suggest that the rotational axis position of the back support of reclining wheelchairs should be adjustable closer to hip joint.

Carlson and Payette [7] described other techniques for minimizing friction and shear forces in wheelchair seating through orientation of the seat surface, positioning of the foot supports, and use of lowfriction seat cover materials. Aissaoui et al. [8] reported relationships between the angle of the leg support and the peak pressure acting on the ischial tuberosities. The results showed that the peak pressure gradient around the ischial tuberosities increased by $20 \%$ when the leg support angle was changed from $90^{\circ}$ to $45^{\circ}$ with respect to the horizontal plane. Moreover, Aissaoui et al. [9] reported relationships among the rotational axis position of the leg support, sitting posture, and the pressure distribution acting on the ischial tuberosities. The results showed that the sitting posture and the pressure distribution in the leg support elevation were changed by the rotational axis position of the leg support. Regarding the relationship between leg supports and the shear force acting on the buttocks, in our previous study [10], we investigated the influence of the timing of leg support elevation on the shear force acting on the buttocks when a wheelchair's back support was reclined. The results suggested that leg supports should be positioned downward before reclining the back support of a wheelchair to decrease the shear force acting on the buttocks. The locus of the 
Citation: Kobara K, Fujita D, Osaka H, Takahashi H, Suehiro T, et al. (2015) Influence of Leg Support Elevation on Horizontal Force Acting on the Buttocks in a Reclining Wheelchair in Different Rotational Axis Positions of the Back Support. J Ergonomics 5: 142. doi: $10.4172 / 2165-7556.1000142$

Page 2 of 7

back support inclination changed with respect to the rotational axis position of the back support $[4,6]$. This infers that leg support elevation influences the fluctuation of the shear force acting on the buttocks when reclining the back support. Some reclining wheelchairs with the rotational axis position of the back support close to hip joint are sold commercially and used clinically. No studies exist, however, on the relationship between the influence of leg support elevation on the shear force acting on the buttocks and the rotational axis position of the back support. The purpose of this study was to investigate how the influences of leg support elevation on the horizontal force acting on the buttocks in a reclining wheelchair change in various rotational axis positions of the back support.

\section{Materials and Methods}

\section{Participants}

It was presumed that the size and shape of the pelvis and the amount of fat on the buttocks would affect the results of this study. To exclude the influence of this variable, the study participants included 13 healthy adult men without leg or trunk disease (mean age, $22.7 \pm$ 6.9 years; mean height, $171.2 \pm 4.0 \mathrm{~cm}$; mean body weight, $63.2 \pm 9.4$ $\mathrm{kg}$ ). Participants were excluded if they experienced pain while sitting in a chair or if they had back pain or a history of surgery, rheumatism, or neurologic disorders. The study was conducted with the approval of the Research Ethics Committee of Kawasaki University of Medical Welfare (\#415), and informed consent was obtained from all participants prior to participation.

\section{Experimental devices}

We used an experimental chair with electric controls to recline the back support (Hashimoto Artificial Limb Manufacturer, Okayama, Japan). The dimensions of the experimental chair were as follows: back support height, 97 or $104 \mathrm{~cm}$; seat depth, $40 \mathrm{~cm}$; backward angle of seat, $0^{\circ}$; reclining angle of back support, $10-40^{\circ}$; angular velocity at which the back support reclined, $3 \%$. The chair's back support was covered with artificial leather. The rotational axis of the back support, the joint between the seat and back support, was located at the same height as the seat. In addition, by inserting L-shaped pieces at the junction of the back support and seat frame, the position of the rotational axis of the back support could be adjusted without altering the relative positions of the back support or seat frame. By inserting Lshaped pieces, as the back support reclined, the bottom edge of the back support shifted downward from the rotational axis of the back support and the distance between the seat and the top of the back support decreased by $50 \mathrm{~mm}$. The experimental chair had leg supports to elevate the legs. The elevation angle of the leg supports could be adjusted between $10^{\circ}$ and $80^{\circ}$ from the vertical plane. The rotational axes of the leg supports, which the joint between the seat and the top edge of the leg support frame, were located at the same height as the seat (Figure 1).

Measurements were obtained while each participant sat comfortably with bilateral symmetry and rested on the back support and force plate located on the chair seat. Hirose [11] reported that inclinations of the sternum and abdominal line are correlated with inclinations of the thoracic and lumbar spine in both the frontal and sagittal planes. Therefore, the posture of each participant was checked, by visually and manually inspecting the sternum and abdominal line, to ensure that the thoracic and lumbar spine in the frontal plane did not lean laterally.

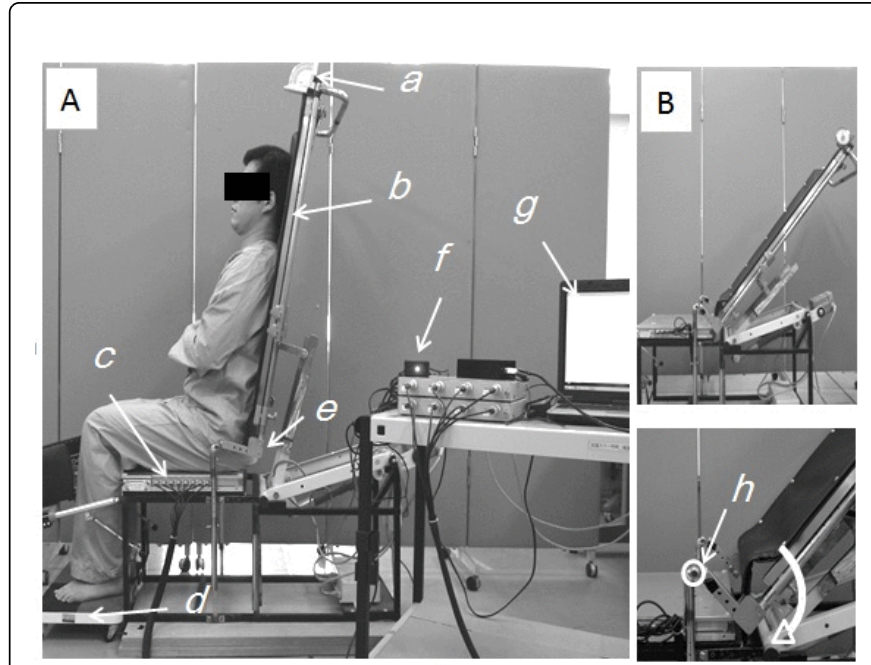

Figure 1: A) Experimental devices, B) Decreasing the distance between the seat and the top of the back support in the trochanteraxis position. The dimensions of the experimental chair were as follows: back support height, 97 or $104 \mathrm{~cm}$; seat depth, $40 \mathrm{~cm}$; backward angle of seat, $0^{\circ}$; reclining angle of back support, 10-40 ; angular velocity at which the back support reclined, $3 \%$ s. a: Level goniometer, b: Back support, c: Force plate, d: Roller boad, e: Lshaped piece, f: Light to synchronize between data of reaction force and video, g: Personal computer, h: rotational axis of the back support.

In addition, to maintain constant friction between the clothing of each participant and the seat surface, all participants wore $100 \%$ cotton clothing for the experiment. Because the smooth metal surface of the force plate was conducive to the participant sliding forward in the chair, a rubber net was laid over the plate to minimize sliding and the risk of postural collapse. The coefficients of friction were calculated on the basis of the maximum static friction force, measured using a pulltension gauge and weight. The measured coefficients of friction between the clothing and the rubber net, between the rubber net and the surface of the force plate, and between the surface of the back support and the clothing were $0.9,0.8$, and 0.4 , respectively. The participants were instructed to fold their arms in front of their chests in a relaxed state and to not intentionally change their body position during the experiment. Kemmoku et al. [12] reported that the vertical and horizontal forces acting on the sacrococcygeal and ischial tuberosity areas increase in a seated posture as the angle of pelvic tilt increases. Thus, to ensure consistency in the pelvic tilt angle, each participant's buttocks were positioned so that their dorsal surface was in contact with the back support.

Two positions of the rotational axis of the back support were evaluated. In the rear- axis position as the control condition, the rotational axis of the back support was located at the same height as the seat and the joint between the seat and back support, which was defined as the point farthest back in the seat. In the trochanter-axis position, the rotational axis was located at $13 \mathrm{~cm}$ in front of the point farthest back in the seat and $7.5 \mathrm{~cm}$ above the seat, so that the buttocks-trochanterion distance in a seated position was $12.8 \pm 1.1 \mathrm{~cm}$ and the height of the trochanterion above the seat was $7.1 \pm 7.0 \mathrm{~cm}$ in a young Japanese adult male [13]. Moreover, we tested two positions of 
Citation: Kobara K, Fujita D, Osaka H, Takahashi H, Suehiro T, et al. (2015) Influence of Leg Support Elevation on Horizontal Force Acting on the Buttocks in a Reclining Wheelchair in Different Rotational Axis Positions of the Back Support. J Ergonomics 5: 142. doi: $10.4172 / 2165-7556.1000142$

the lower legs in each the rotational axis position. In the leg-down condition, the positions of the lower legs was adjusted to be perpendicular to the feet on the floor, and the horizontal thigh angle was then adjusted by stacking wooden boards under the experimental chair. Furthermore, to reduce the resistance of the lower extremities, a roller board was placed under the participants' feet. In contrast, in the leg-up condition, the leg supports were elevated to position the lower legs at an $80^{\circ}$ incline from vertical. Thus, four experimental conditions were used in the present study, namely the leg-down condition in both the rear-axis and the trochanter- axis positions and the leg-up condition in both the rear-axis and the trochanter- axis positions. Aissaoui et al. [9] reported the angulations of the lower leg supports can affect an individual's hip posture if the angulation changes the distance from the seat front to the foot plates. This distance changes because the leg support's axis of motion is not aligned with the knee joint axis. This interdependency between the leg support angle and the distance between the footplate and the seat requires the linear placement of the lower leg and foot plate to be adjusted synchronously with the leg support's angulation. In addition, the soles of the feet did not resist the horizontal force acting on the buttocks by kicking the foot plates. Thus, in the leg-up condition in both of the rotational axis positions, the foot plates were not used in the present study (Figure 2).

\section{Methods for measurements}

To investigate the cause of the increased shear force acting on the buttocks, we measured the horizontal and normal forces when the back support was reclined. In addition, we also measured the trunk sliding distance along the back support to examine how the shear force increased. The North American National Pressure Ulcer Advisory Panel [14] defines "shear" as "an action or stress resulting from applied forces which causes or tends to cause two contiguous internal parts of the body to deform in the transverse plane." As measuring shear force is difficult, we measured the horizontal and normal forces to determine the shear force as in the previous study by Kemmoku et al. [12]. The horizontal and normal forces acting on the buttocks were measured using a force plate ( $400 \times 400 \mathrm{~mm}$; sampling frequency, $100 \mathrm{~Hz}$; Kyowa Electronic Instruments, Tokyo, Japan) that measured the reaction force in the posterior direction, which is equivalent to the horizontal force in the anterior direction while the back support is inclined. We also measured the trunk sliding distance along the back support, by using a video camcorder. Videos of the trunk and back support were taken from the left side using a digital video camera (Panasonic, Osaka, Japan) for the duration of the back support movement. Dartfish TeamPro Data 6.0 video analysis software (Dartfish, Fribourg, Switzerland) was used to measure the trunk sliding distance along the back support. This distance was defined as follows:

$$
\mathrm{BS}=\mathrm{Va}-\mathrm{Vi}
$$

Where, BS is the distance the trunk slid along the back support, and $\mathrm{Va}$ and $\mathrm{Vi}$ correspond to the distance between the acromion and the reference basis point, projected on the back support plane, in a reclining back support position (a) and an initial upright position (i), respectively (Figure 3) [15]. A positive value indicates that the trunk slid down from the starting position.
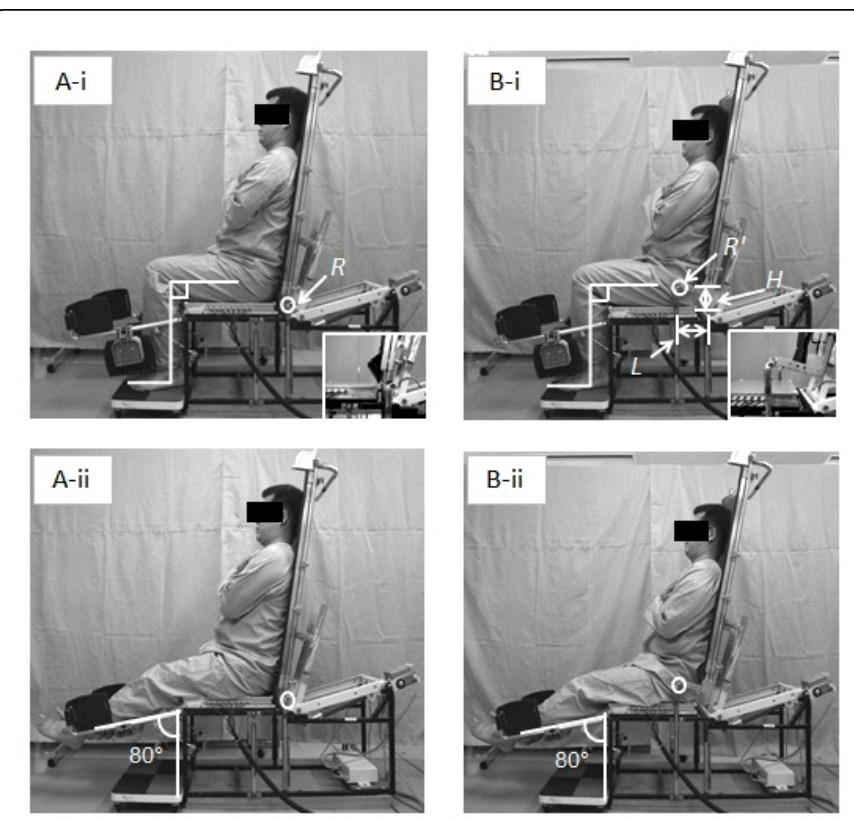

Figure 2: Measured posture and Experimental conditions. A. The rear-axis position, $B$. The trochanter-axis position, i) The leg-down condition, ii) The leg-up condition. Measurements were obtained as each participant sat comfortably with bilateral symmetry and rested on the back support and force plate located on the chair seat. R, R': Rotational axis of back support; $\mathrm{H}$ : distance between the rotational axis and surface of force plate $(7.5 \mathrm{~cm})$; L: distance between the rotational axis and back seat $(13 \mathrm{~cm})$. The elevation angle of the leg supports could be adjusted between $10^{\circ}$ and $80^{\circ}$ backward from the vertical.

To avoid postural collapse, measurements were performed 10 seconds after the posture was set. With respect to the angle of the back support, Park et al. [16] reported that decubitus ulcers may be prevented or diminished in tetraplegia patients when the back support angle of the wheelchair is more than $120^{\circ}$, which is equivalent to $30^{\circ}$ from vertical. Accordingly, the experimental back support was reclined at increasing angles, beginning at $10^{\circ}$ from vertical (the initial upright position [IUP]) and proceeding to a fully reclined position (FRP) of $40^{\circ}$ from vertical. The position of the lower legs was set according to the experimental condition before the back support was reclined. Between each condition, the participants were asked to stand up and relax for one minute to release the force on the back support and the seat. In both rotational axis positions, the time required to measure the forces in each back support position was 5 seconds. For each experimental condition, we used the average of the forces acting on the buttocks after measuring 201 stable samples for each participant. The four conditions were measured with three trials for each experimental condition. The 12 trials were measured in random order. If the participant could not continue sitting because of intolerance of the position or danger of sliding out of the wheelchair, the experiment was stopped for safety reasons. Between each trial, the participants were asked to rest and relax for one minute. 
Citation: Kobara K, Fujita D, Osaka H, Takahashi H, Suehiro T, et al. (2015) Influence of Leg Support Elevation on Horizontal Force Acting on the Buttocks in a Reclining Wheelchair in Different Rotational Axis Positions of the Back Support. J Ergonomics 5: 142. doi: $10.4172 / 2165-7556.1000142$

Page 4 of 7

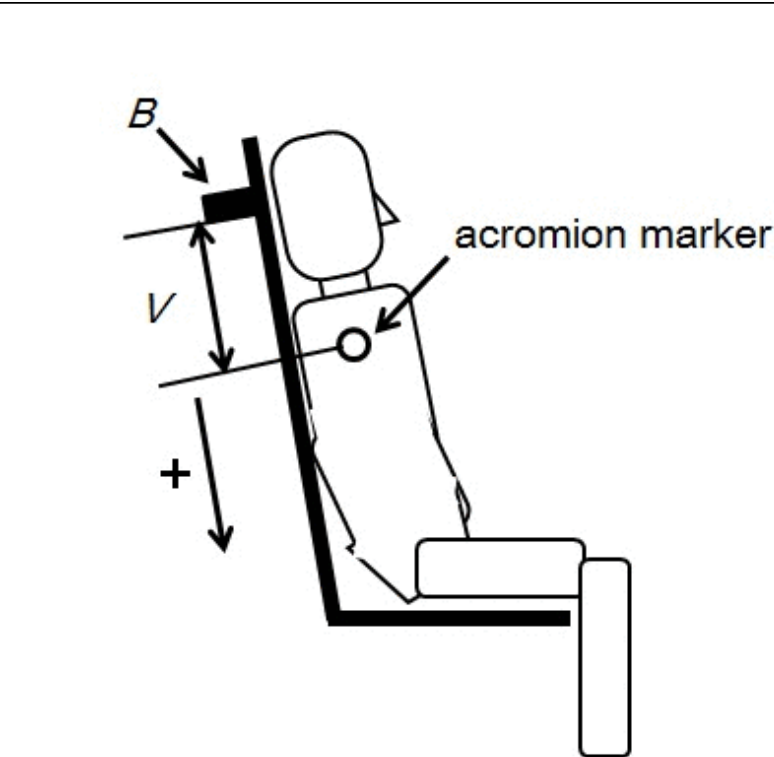

Figure 3: The definition of sliding distance along the back support15: distance between reference point $\mathrm{B}$ and the acromion marker along the back support plane. B: the basis of point on the back support. +: the trunk slid down from the starting position.

To correct for the effects of body weight, the measured horizontal and normal forces acting on the buttocks were normalized by body weight (percent body weight), on the basis of the raw data from the force plate. Moreover, to investigate how the influence of leg support elevation on the shear force acting on the buttocks in a reclining wheelchair changes in different rotational axis positions of the back support, we calculated the variation rate of the forces acting on the buttocks between the FRP and the IUP (FRP/IUP*100; \%).

\section{Statistical Analyses}

Preliminary analysis of the forces acting on the buttocks and the sliding distance along the back support was performed using the Shapiro-Wilk normality test. To investigate the influence of elevating the leg supports in each position of the rotational axis, the forces acting on the buttocks and the sliding distance were compared between the two experimental conditions in the reclining position for each rotational axis position of the back support. In addition, to investigate the influence of reclining the back support, the forces were compared between the IUP and the FRP in each rotational axis position of the back support. The data were analyzed using paired t-tests. The statistical analyses were performed using the Statistical Package for the Social Sciences (SPSS) version 16.0 J for Windows (SPSS, Chicago, IL, USA). The level of significance was set at $\mathrm{p}<0.05$.

\section{Results}

Tables 1 and 2 show the horizontal and normal forces acting on the buttocks, Table 3 shows the sliding distance along the back support.

\section{Horizontal force acting on the buttocks}

In terms of the horizontal forces, significant differences were measured between the leg-down and leg-up conditions in each of the two reclining positions for both rotational axis positions of the back support $(\mathrm{p}<0.01)$. There were no significant differences between the two positions of the back support in the rear-axis position (leg-down: $\mathrm{p}=0.89$, leg-up: $\mathrm{p}=0.14$ ), and there were significant differences between the two positions of the back support in the trochanter-axis position $(\mathrm{p}<0.01)$. There were significant differences in the variation rate between the leg-down and leg-up conditions in the trochanter-axis position $(\mathrm{p}<0.01)$. Moreover, there were significant differences in the horizontal force in the FRP and the variation rate between the two positions of the rotational axis of the back support (Table 1).

\begin{tabular}{|c|c|c|c|}
\hline \multicolumn{4}{|l|}{$n=13$} \\
\hline & & $\begin{array}{l}\text { The leg-down } \\
\text { condition a }\end{array}$ & $\begin{array}{l}\text { The leg-up } \\
\text { condition a }\end{array}$ \\
\hline \multirow{4}{*}{ The rear-axis } & $\operatorname{IUP}(\% B W)^{* *}$ & $10.2 \pm 1.1 \mathrm{c}$ & $15.9 \pm 2.3 c$ \\
\hline & $\mathrm{FRP}(\% \mathrm{BW})^{\star *}$ & $10.2 \pm 1.0 \mathrm{~d}$ & $15.1 \pm 1.5 \mathrm{~d}$ \\
\hline & $\begin{array}{l}\text { the variation } \\
\text { rate }(\%) \text { n.s. }\end{array}$ & $100.7 \pm 16.7 \mathrm{~d}$ & $96.3 \pm 10.2 d$ \\
\hline & & $\begin{array}{l}\text { The leg-down } \\
\text { condition b }\end{array}$ & $\begin{array}{l}\text { The leg-up } \\
\text { condition b }\end{array}$ \\
\hline \multirow{3}{*}{$\begin{array}{l}\text { The } \\
\text { trochanter- } \\
\text { axis }\end{array}$} & $\operatorname{IUP}(\% B W)^{\star *}$ & $9.9 \pm 2.3$ & $16.2 \pm 1.6$ \\
\hline & $\mathrm{FRP}(\% \mathrm{BW})^{* *}$ & $15.1 \pm 2.5$ & $19.2 \pm 1.9$ \\
\hline & $\begin{array}{l}\text { the variation } \\
\text { rate }(\%)^{\star *}\end{array}$ & $155.6 \pm 29.1$ & $119.3 \pm 10.7$ \\
\hline \multicolumn{4}{|c|}{$\begin{array}{l}\text { mean } \pm S D, * *: p<0.01 \text { (compared between the leg-down and the leg-up } \\
\text { conditions) }\end{array}$} \\
\hline \multicolumn{4}{|c|}{$\%$ BW: Percent body weight } \\
\hline \multicolumn{4}{|c|}{ a: Not significant (compared with two positions of back support) } \\
\hline \multicolumn{4}{|c|}{$\mathrm{b}: \mathrm{p}<0.01$ (compared with two positions of back support) } \\
\hline \multicolumn{4}{|c|}{ c: Not significant (compared with the rotational axis position) } \\
\hline \multicolumn{4}{|c|}{$\mathrm{d}: \mathrm{p}<0.01$ (compared with the rotational axis position) } \\
\hline
\end{tabular}

Table 1: Horizontal force acting on buttocks on various position of the back support.

\section{Normal force acting on the buttocks}

In terms of the normal forces, significant differences were measured between the leg-down and leg-up conditions in each of the two reclining positions for both rotational axis positions of the back support $(\mathrm{p}<0.01)$. In addition, there were significant differences between the two positions of the back support for both rotational axis positions of the back support $(\mathrm{p}<0.01)$. There were no significant differences in the variation rate between the leg-down and leg-up conditions in either position of the rotational axis (rear-axis: $p=0.07$, trochanter-axis: $\mathrm{p}=0.528$ ). Moreover, there were significant differences in the normal force in the FRP and the variation rate between the two positions of the rotational axis of the back support (Table 2). 
Citation: Kobara K, Fujita D, Osaka H, Takahashi H, Suehiro T, et al. (2015) Influence of Leg Support Elevation on Horizontal Force Acting on the Buttocks in a Reclining Wheelchair in Different Rotational Axis Positions of the Back Support. J Ergonomics 5: 142. doi: $10.4172 / 2165-7556.1000142$

Page 5 of 7

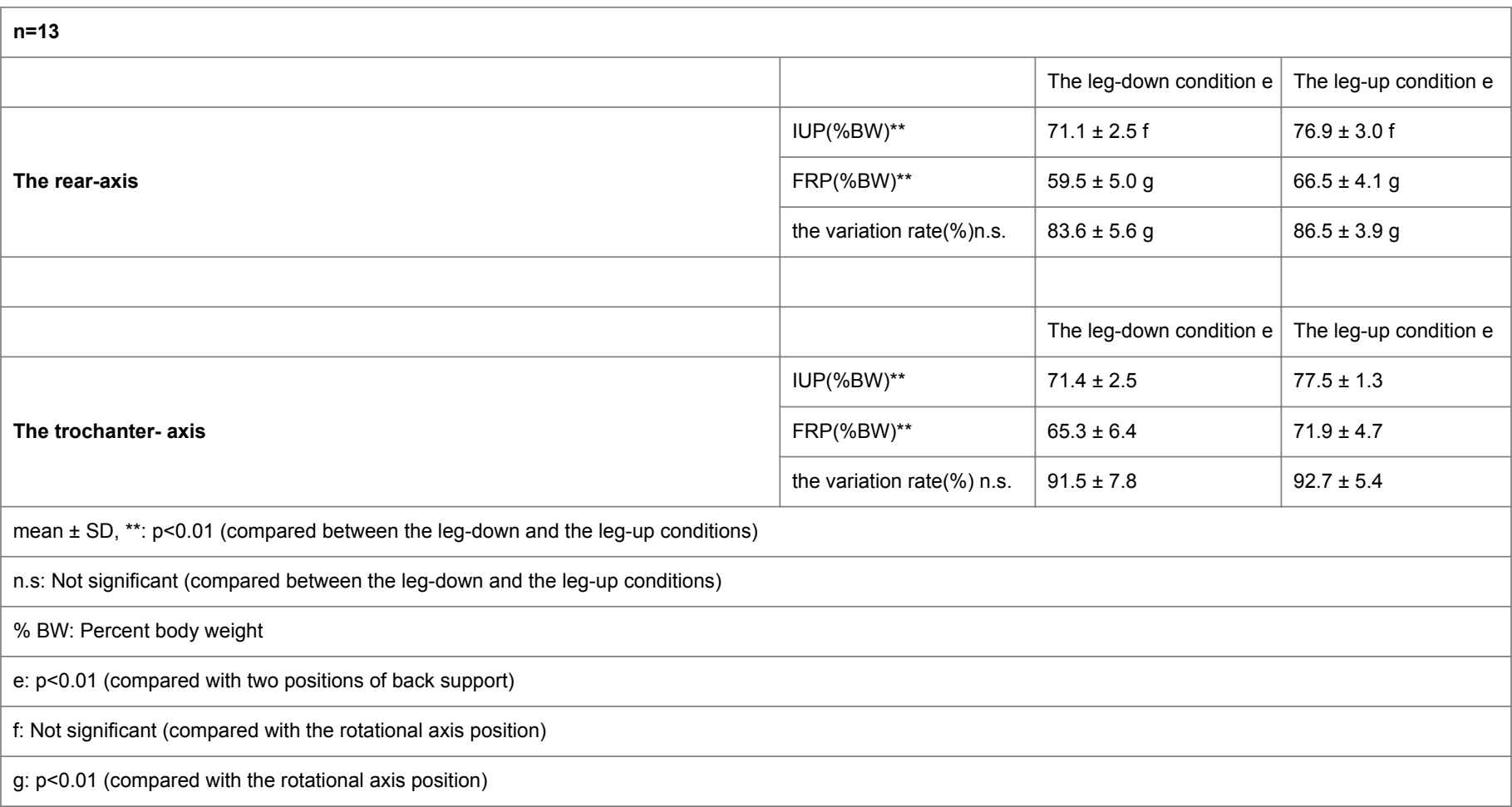

Table 2: Normal force acting on buttocks on various position of the back support.

\section{Trunk sliding distances along the back support}

Regarding the trunk sliding distance along the back support, in the rear-axis position, the differences in the trunk sliding distances of the back support between the leg-down and leg-up conditions were not significant $(\mathrm{p}=0.53)$. In the trochanter-axis position, the differences in were significant $(\mathrm{p}<0.05)$ (Table 3$)$.

\begin{tabular}{|l|l|l|}
\hline & & $\mathbf{n = 1 3}$ \\
\hline & The leg-down condition & The leg-up condition \\
\hline The rear-axis n.s & $78.5 \pm 10.7$ & $80.4 \pm 13.8$ \\
\hline The trochanter- axis* & $-3.5 \pm 6.7$ & $-6.6 \pm 6.6$ \\
\hline mean $\pm \mathrm{SD}(\mathrm{mm})$ & \multicolumn{2}{|l}{} \\
\hline *: $\mathrm{p}<0.05, \mathrm{n} . \mathrm{s}:$ not significant (compared with two experimental conditions) \\
\hline A positive value indicates that the trunk slid down from the starting position. \\
\hline
\end{tabular}

Table 3: Trunk sliding distances along the back support on various rotational axis position.

\section{Discussion}

This study investigated how the influence of leg support elevation on the shear force acting on buttocks in a reclining wheelchair changes in different rotational axis positions of the back support to aid in the prevention of decubitus ulcers in individuals who use wheelchairs with reclining back supports.

\section{Changes to the horizontal force by reclining the back support}

After the back support was inclined, the horizontal forces acting on the buttocks in the leg-down and leg-up conditions were significantly increased in the trochanter-axis position of the rotational axis and did not significantly increase in the rear-axis position. These results might be caused by the difference in the rotational axis position of the back support [4-6]. In the trochanter-axis position in this study, the trunk slid upward along the back support, and the distance the trunk slid was very small. These findings suggested that the trunk and pelvis were inclined with the back support as it reclined while remaining parallel to it because the rotational axis of the back support and the rotational axis of the trunk and pelvis, the hip joint, were close together. Furthermore, the rotational axis of the experimental chair's back support in this study was changed by inserting L-shaped pieces at the junction of the back support and seat frame. Therefore, the bottom edge of the back support shifted forward and downward from the rotational axis of the back support, and the distance between the seat and the top of the back support decreased by $5 \mathrm{~cm}$ when the back support reclined to 40 degrees. Therefore, the leg-down and leg-up conditions in the trochanter-axis position caused the length of the back support to shorten and increased the horizontal force significantly as the trunk slid forward and downward on the back support.

\section{The deference in the rotational axis position of the back support}

We describe below considerations about how the influence of leg support elevation on the shear force acting on the buttocks in a reclining wheelchair changes in different rotational axis positions of the back support. In the IUP and FRP in both the rotational axis positions, the horizontal force in the leg-up condition was significantly 
higher than in the leg-down condition. The lower legs were elevated by the leg supports in the leg-up condition. The angle of the lower legs was $10^{\circ}$ downward from the horizontal plane when the leg supports were maximally elevated. The inclination of the leg supports and the mass of the lower legs resulted in rotating the thighs forward. In the leg-up condition in both rotational axis positions, the normal force on the seat was significantly increased. These findings suggest that the leg supports used in this study did not sufficiently support the mass of the lower legs [10]. In the leg-up condition in both rotational axis positions, as described above, the pelvis was pulled forward and downward the thighs were not able to completely support the mass of the lower legs. In addition, the angle of backward pelvic tilt was increased by extending the hamstrings as a result of elevating the leg supports. As a result, the pressure acting on the back support increased. Aissaoui et al. [9] reported that the pressure on the back support while sitting on a chair increased by elevating the leg supports. Moreover, Kemmoku et al. [12] reported that the horizontal force acting on the sacrococcygeal and ischial tuberosity areas while seated increases as the pelvic tilt angle increases. In addition, our previous study reported a strong relationship between the reaction force on the back support and the horizontal force acting on the buttocks $[17,18]$. The pressure, that is, the reaction force, on the back support is increased by increasing the angle of backward pelvic tilt. Because of the effect of the reaction force on the back support and the force pulling the thigh mass forward and downward as described above, it might be presumed that the horizontal force acting on the buttocks in the leg-up condition increased significantly in the IUP [10].

Incidentally, when the back support was inclined, the pressure on the back support as a result of the pelvic tilt extending the hamstrings decreased in the leg-up condition. In a previous study by Gilsdorf et al. [19], moreover, the normal force on a hard surface seat similar to this study was measured with various thigh angles from $20^{\circ}$ downward to $10^{\circ}$ upward from the horizontal plane in a seated position. The pressure under the $20^{\circ}$ downward condition showed a smaller value than the other conditions. These results suggested that the pelvis was lifted forward and upward by the torque to forward that the mass of lower legs occurred through the thighs in sitting on a chair on deficiently supported the mass of lower legs. From these findings, it might be presumed that in the FRP the forces on the back support in the leg-up condition were decreased compared to the leg-down condition. The maximum static friction force just before sliding forward of the lower legs occurs is defined as follows:

Ffric.stat.max $=\mathrm{f}^{\star} \mathrm{FN}$

Where, $\mathrm{f}$ is the friction coefficient and FN is the normal force (the force in the vertical direction) on the surface of the back support. This implies that in regions where the normal force is relatively high, the static friction can become high as well. In addition, in this study, the trunk in the leg-up condition slid upward significantly compared to the leg-down condition. Therefore, it might be presumed that the maximum static friction force between the back support and the trunk was decreased by decreasing the pressure on the back support in the leg-up condition in the trochanter-axis position. On the other hand, there were no significant differences in the trunk sliding distance between the leg-down and leg-up conditions in the rear-axis position. In the rear-axis position, the trunk was supported by the buttocks because the trunk slid downward when reclining, unlike the trochanter-axis position. Thus, if there were differences in the static friction between the back support and the trunk between the leg-down and the leg-up condition, it might be presumed that the differences in the trunk sliding distances were not significant. In other words, it might be presumed that the friction force between the back support and the trunk in the trochanter-axis position was also decreased by insufficient support of the mass of the lower legs as described above. In this manner, in the leg-up condition in both axis positions, the resistance force to the pulling force of the mass of the lower legs on the buttocks decreased because the maximum static friction force between the back support and the trunk decreased. Therefore, the horizontal force acting on the buttocks in the leg-up condition was significantly higher than in the leg-down condition in the FRP in both rotational axis positions.

However, the variation rate of the horizontal force acting on buttocks showed differences between the two rotational axis positions. The variation rate of the horizontal force in the leg-up condition was significantly lower than in the leg-down condition in the trochanteraxis position, but there were no significant differences in the rear-axis position. In both leg conditions in the FRP, the normal force acting on buttocks in the trochanter-axis position was significantly higher than in the rear-axis position. Moreover, as described above, the distance the trunk slid upward in the leg-up condition in the trochanter-axis position was significantly higher than in the leg-down condition. These results suggested that in the leg-up condition the loaded force acting on the buttocks was released because the trunk slid upward on the back support by the reaction force against the stronger normal force led to the length of the back support in the back support was shortened as it reclined. Therefore, in the FRP in the trochanter-axis position, the variation rate of the horizontal force acting on the buttocks in the legup condition showed a significantly lower value than in the leg-down condition.

The main limitation of this study is that it included only healthy adult males. In addition, because the measurement times were short, the effect of delayed postural collapse was not evaluated. Furthermore, the form (i.e., the rotational axis position of the leg support), material, and coefficient of friction of the experimental wheelchair's seat differed from those used to measure the horizontal forces. For example, foot plates were not used in this study so that the soles of the feet did not resist the horizontal force acting on the buttocks by kicking the foot plates. If foot plates had been used in this study, it might be presumed that the fluctuation of the horizontal force acting on the buttocks under the leg-up condition was decreased by resistance to the parallel force forward and downward on the leg support. Moreover, we did not consider factors that interact with the friction force, such as urinary incontinence and sweat, which affect many wheelchair users. Therefore, the present results should be extrapolated to actual wheelchair users with great caution.

\section{Conclusion}

The results of this study suggest that the extent of the influences of leg support elevation on the shear force acting on the buttocks in a reclining wheelchair decreases when the rotational axis of the back support is placed close to the trochanter. In addition, the static friction force between the back support and the trunk should be considered to prevent decubitus ulcer formation. In the future, we plan to investigate the influences of the seat material and the friction force of the back support on the horizontal force acting on the buttocks while the wheelchair is reclining. These results will aid in the development of reclining wheelchairs and ultimately reduce the occurrence of decubitus ulcers. 
Citation: Kobara K, Fujita D, Osaka H, Takahashi H, Suehiro T, et al. (2015) Influence of Leg Support Elevation on Horizontal Force Acting on the Buttocks in a Reclining Wheelchair in Different Rotational Axis Positions of the Back Support. J Ergonomics 5: 142. doi: $10.4172 / 2165-7556.1000142$

Page 7 of 7

\section{Acknowledgment}

This study was supported by JSPS KAKENHI Grant Number 26750234. All authors contributed equally to the preparation of this manuscript.

\section{Conflict of Interest}

The authors have no conflicts of interest to report.

\section{References}

1. http://www.npuap.org/resources/educational-and-clinical-resources/ npuap-pressure-ulcer-stagescategories/

2. Husain T (1953) An experimental study of some pressure effects on tissues, with reference to the bed-sore problem. J Pathol Bacteriol 66: 347-358.

3. Hanson D, Langemo DK, Anderson J, Thompson P, Hunter S (2010) Friction and shear considerations in pressure ulcer development. Adv Skin Wound Care 23: 21-24.

4. Kobara K, Osaka H, Takahashi H, Ito T, Fujita D, et al. (2014) Effect of rotational axis position of wheelchair back support on shear force when reclining. J Phys Ther Sci 26: 701-706.

5. Kobara K, Fujita D, Osaka H, Ito T, Watanabe $S$ (2013) Influence of distance between the rotation axis of back support and the hip joint on shear force applied to buttocks in a reclining wheelchair's back support. Prosthet Orthot Int 37: 459-464.

6. Kobara K, Osaka H, Takahashi H, Ito T, Fujita D, et al. (2015) Influence of height of back support rotational axis on shear force applied to buttocks in a reclining wheelchair back support. Prosthet Orthot Int 38.

7. Carlson JM, Payett MJ, Vervena LP (1995) Seating orthosis design for prevention of decubitus ulcers. J Prosthet Orthot 7: 51-60.

8. Aissaoui R, Dansereau J, Lalonde N, Lacoste M (1998) Repositioning the able-bodied: Effect of the shape cushion on pressure distribution. In Proc. RESNA, Mineapolis, MN, 110-112.
9. Aissaoui R, Heydar S, Dansereau J, Lacoste M (2000) Biomechanical analysis of legrest support of occupied wheelchairs: Comparison between a conventional and a compensatory legrest. IEEE Trans Rehabil Eng 8: $140-148$.

10. Kobara K, Takahashi H, Fujita D, Osaka H, Ito T, et al. (2015) Investigation of effect of leg support elevation timing on the horizontal force acting on the buttocks in a reclining wheelchair. J Phys Ther Sci 27: 2605-2610.

11. Hirose H (2005) Development of clinical methods for measuring geometric alignment of the thoracic and lumbar spines of wheelchairseated persons. J Rehabil Res Dev 42: 437-446.

12. Kemmoku T, Furumachi K, Shimamura $T$ (2013) Force on the sacrococcygeal and ischial areas during posterior pelvic tilt in seated posture. Prosthet Orthot Int 37: 282-288.

13. Kouchi M, Mochimaru M, Iwasawa H, Mitani S (2000) Anthropometric database for Japanese Population1997-98 [in Japanese]. Japanese Industrial Standards Center.

14. http://www.npuap.org/wp-content/uploads/2012/03/Shear slides.pdf

15. Aissaoui R, Lacoste M, Dansereau J (2001) Analysis of sliding and pressure distribution during a repositioning of persons in a simulator chair. IEEE Trans Neural Syst Rehabil Eng 9: 215-224.

16. Park UJ, Jang SH (2011) The influence of backrest inclination on buttock pressure. Ann Rehabil Med 35: 897-906.

17. Kobara K, Eguchi A, Watanabe S, Ishiura Y, Fujita D, et al. (2008) Investigation of the validity of an experimental model for the estimated shear force on buttocks in a comfortable sitting posture. J Phys Ther Sci 20: $157-162$.

18. Kobara K, Shinkoda K, Watanabe S, Eguchi A, Fujita D, et al. (2011) Investigation of validity of model for estimating shear force applied to buttocks in elderly people with kyphosis while sitting comfortably on a chair. Disabil Rehabil Assist Tech 8: 220-224.

19. Gilsdorf P, Patterson R, Fisher S, Appel N (1990) Sitting forces and wheelchair mechanics. J Rehabil Res Dev 27: 239-246. 